\title{
Pseudohyponatraemia, hypercholesterolaemia, and primary biliary cirrhosis
}

\author{
P E HICKMAN, K P DWYER, J R L MASAREI \\ From the Department of Biochemistry, Royal Perth Hospital, Western Australia
}

SUMMARY A 62 year old woman with primary biliary cirrhosis was found to have a plasma sodium concentration of $115 \mathrm{mmol} / \mathrm{l}$. Follow up showed this to be a "pseudohyponatraemia" due to a massively raised serum cholesterol concentration of $78 \mathrm{mmol} / \mathrm{l}$. Electrophoresis of serum lipoproteins and of the lipoproteins and apolipoprotiens in fractions isolated on density-gradient ultracentrifugation showed that the major portion of the serum cholesterol was being transported with lipoprotein$X$. Low density lipoprotein-cholesterol concentration was also raised. Lipoprotein-X contained, in addition to albumin and apolipoprotein $\mathrm{C}$, apolipoprotein $\mathrm{E}$.

This case is of interest because of the degree of hypercholesterolaemia, its association with pseudohyponatraemia, and the unequivocal demonstration of apolipoprotein $\mathrm{E}$ associated with lipoprotein-X.

Primary biliary cirrhosis is a disease of unknown aetiology, characterised by gradual destruction of bile ducts, and leading to hepatocyte loss and liver scarring. Among the many laboratory features that may accompany it are increases in serum lipid concentrations, especially of cholesterol. Cholesterol concentrations are invariably above the reference range and may be as high as $15 \mathrm{mmol} / \mathrm{l}^{1}$

We report a case of primary biliary cirrhosis in which follow up of a low plasma sodium concentration led to the finding of a massively raised cholesterol concentration of $78 \mathrm{mmol} / \mathrm{l}$.

\section{Material and methods}

Electrolytes and liver function tests were measured on a SMAC II AutoAnalyzer (Technicon Equipment, Sydney, Australia) with Technicon reagents and methods. Sodium and potassium were also measured on a Corning Model $902 \mathrm{Na} / \mathrm{K}$ Analyzer (Corning Instruments, Halstead, Essex, England). Coefficients of variation (CVs) for sodium were $1.3 \%$ at $115 \mathrm{mmol} /$ 1 and $0.8 \%$ or less at $155 \mathrm{mmol} / \mathrm{l}$.

Serum cholesterol and triglyceride concentrations were measured on a Cobas Mira (Roche Diagnostics, Sydney, Australia) discrete analyser, using A-gent reagents (Abbott Laboratories, Irving, Texas). CVs for cholesterol at three control levels were better than $3 \%$. The lipid assays were standardised using calibrators with values traceable to the Centers for Disease Control, Atlanta, Georgia, United States of America. Serum lipoprotein and protein electrophoresis were performed on a Beckman Paragon Electrophoresis System (Beckman Instruments, Sydney, Australia) using Beckman reagents.

Density gradient ultracentrifugation (isopycnic) was performed by a modification of the method of Redgrave et al on a sample collected four weeks after the initial study. ${ }^{2}$ At this time the total cholesterol concentration was $64.8 \mathrm{mmol} / \mathrm{l}$. The procedure was performed on the smaller Beckman SW60 rotor at $54000 \mathrm{rpm}$ for 16 hours and samples were diluted $1 / 1 \cdot 5$ with physiological saline to prevent the high lipid content from overloading the gradient. After centrifugation the densities of the fractions obtained ranged from 1.017 to $1.260 \mathrm{~kg} / \mathrm{l}$. Each fraction was aspirated and weighed and the cholesterol content determined. The qualitative apolipoprotein composition of each fraction was obtained by polyacrylamide gel electrophoresis in the presence of sodium dodecyl sulphate (SDS). The method was based on that of Laemmli (1970). ${ }^{3}$ Briefly, 3\%-24\% gradients were prepared in $1.5 \mathrm{~mm}$ thick vertical slabs (Hoeffer Instruments, San Francisco, California, United States of America) and electrophoresis performed at 20 watts per slab for three hours. Glycerol was incorporated into the resolving gel at a concentration of $18 \%$ and into the stacking gel at a concentration of $10 \% .{ }^{4}$ The applied densities were determined with a Paar density meter (Anton Paar, Graz, Austria) and the densities of the 


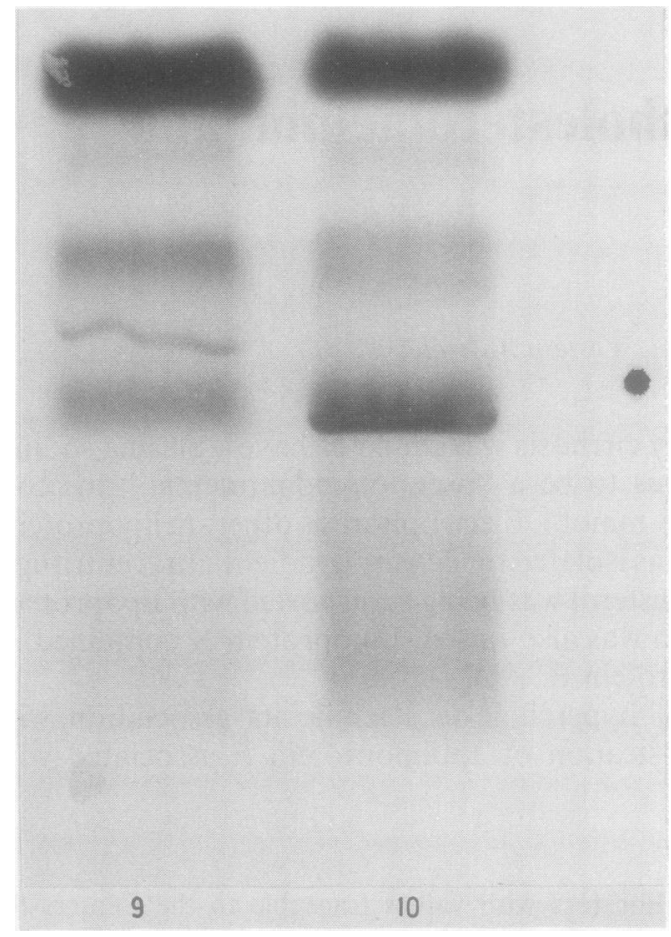

Fig 1 Serum protein electrophoresis. Serum protein electrophoresis was run on agarose (Beckman Paragon) and stained with amido black. Patient's serum is on the right, the pattern on the left is from a patient showing normal electrophorectic mobility of the protein classes. The $\beta$ band on the right is unusually intense and has a slightly slower mobility than that on the left.

recovered fractions were determined with a micropycnometer.

Apolipoprotein (apo) B was measured by radial immunodiffusion using plates and standards from Immuno (Vienna, Austria).

\section{CASE REPORT}

A 62 year old woman with a long established diagnosis of primary biliary cirrhosis was admitted to hospital to undergo liver biopsy for more accurate staging of her disease. The biopsy proceeded uneventfully and she was discharged two days later. Liver function tests done at the time of admission included bilirubin $108 \mu \mathrm{mol} / 1$ (reference range $<20 \mu \mathrm{mol} / \mathrm{l}$ ), alkaline phosphatase (EC 3.1.3.1) $1940 \mathrm{U} / \mathrm{L}$ (40-135), and aspartate aminotransferase (EC 2.6.1.1) $110 \mathrm{U} / \mathrm{L}$ (6-42).

Electrolytes were also measured on admission. Sodium concentration (measured by ion-selective electrode with specimen dilution) was reported as equivalent to $115 \mathrm{mmol} / \mathrm{l}$ (reference interval 134-146). Because the patient had no symptoms that could be related to a hyponatraemia of this degree we elected to check this measurement on a direct reading ion-selective electrode without dilution and obtained a valve equivalent to $134 \mathrm{mmol} / \mathrm{l}$. This "pseudohyponatraemia" is indicative of a high concentration in the blood of a high molecular weight substance such as protein or lipid, reducing the water content of the plasma.

Total protein concentration was $70 \mathrm{~g} / 1$ and serum protein electrophoresis showed a normal pattern except for a dense band in the $\beta$ region, with slightly slower mobility than normal $\beta$-lipoprotein (fig 1 ). There was a polyclonal increase in immunoglobulins, and increased concentrations of the three major classes of immunoglobulins were confirmed on quantitation. (IgG $17 \cdot 3 \mathrm{~g} / \mathrm{l}$, reference range $6 \cdot 0-14.3 \mathrm{~g} / \mathrm{l}$ ); $\operatorname{IgM} 8.4 \mathrm{~g} / 1$ (0.3-1.8); and $\operatorname{IgA} 3.9 \mathrm{~g} / 1$ (0.65-3.4). Immunofixation (Beckman Instruments, Sydney,

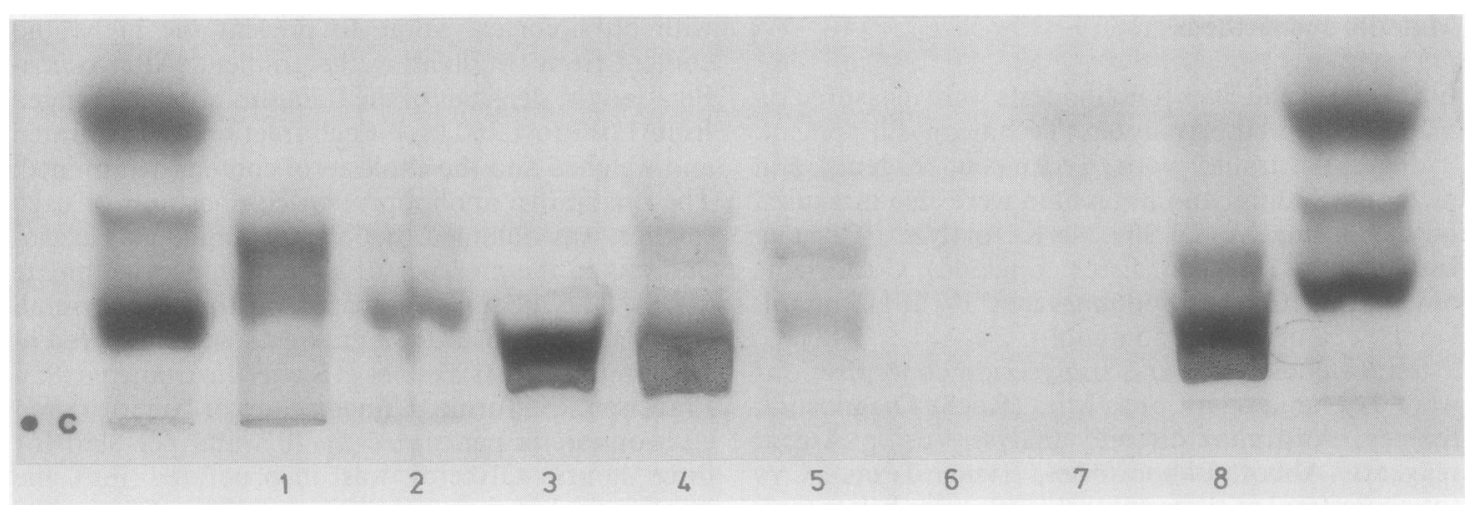

Fig 2 Lipoprotein electrophoresis. At the margins (unnumbered columns) are samples of unfractionated normal control serum. Column 8 is diluted but unfractionated patient's serum. Columns 1-7 represent the fractions of increasing density obtained by density-gradient ultracentrifugation (1) 1.017 ; (2) 1.029 ; (3) 1.069 ; (4) 1.094 ; (5) $1 \cdot 13$; (6) $1 \cdot 191$; (7) $1 \cdot 26 \mathrm{~kg} / \mathrm{l}$. 
Table Cholesterol content of fractions obtained by densitygradient ultracentrifugation

\begin{tabular}{llcc}
\hline $\begin{array}{l}\text { Density } \\
(\mathrm{kg} / \mathrm{l})\end{array}$ & $\begin{array}{l}\text { Volume } \\
(\mathrm{ml})\end{array}$ & $\begin{array}{l}\text { Cholesterol } \\
\text { concentration } \\
(\mathrm{mmol} / \mathrm{l})\end{array}$ & $\begin{array}{l}\text { Total } \\
\text { cholesterol } \\
(\mu \mathrm{mol} / \mathrm{l})\end{array}$ \\
\hline 1.017 & 0.451 & 1.91 & 0.86 \\
1.029 & 0.920 & 8.45 & 7.77 \\
1.069 & 0.643 & 21.85 & 14.04 \\
1.094 & 0.351 & 2.61 & 0.92 \\
1.113 & 0.626 & 0.42 & 0.26 \\
1.191 & 0.812 & 0.01 & 0.01 \\
1.260 & 0.588 & 0.12 & 0.07 \\
Totals & 4.391 & & 23.93 \\
\hline
\end{tabular}

Australia) did not show any monoclonal bands.

The serum specimen was optically clear and the triglyceride concentration $3.5 \mathrm{mmol} / \mathrm{l}$. Cholesterol concentration on the initial specimen was $78 \mathrm{mmol} / \mathrm{l}$. A further sample was obtained and the cholesterol concentration was $76 \mathrm{mmol} / \mathrm{l}$.

Lipoprotein electrophoresis of unfractionated serum (fig 2 , column 8 ) showed a dense band lying cathodal to the usual low density lipoprotein (LDL) position, and corresponding to the reported position of lipoprotein-X.5 Density-gradient ultracentrifugation was performed and the fractions isolated were subjected to lipoprotein electrophoresis as shown in fig 2, columns 1 to 7. The LDL and lipoprotein-X segregated predominantly into the fractions of density 1.029 and $1.069 \mathrm{~kg} / \mathrm{l}$, respectively (fig 2 , columns 2 and 3).

\section{Results}

The cholesterol content of each fraction was estimated and the results are shown in the table. The density gradient was prepared by the method of Redgrave $e t$ $a^{2}$ modified for the Beckman SW 60 rotor. The densities are those measured on fractions isolated after centrifugation. The initial serum cholesterol concentration was $64.8 \mathrm{mmol} / \mathrm{l}$. After correcting for gradient generation and a sample dilution of $2.5 \times$ with sodium chloride solution $(154 \mathrm{mmol} / \mathrm{l}$; density $1.006 \mathrm{~kg} / \mathrm{l})$, $23.98 \mu \mathrm{mol}$ of cholesterol were applied to the gradient.

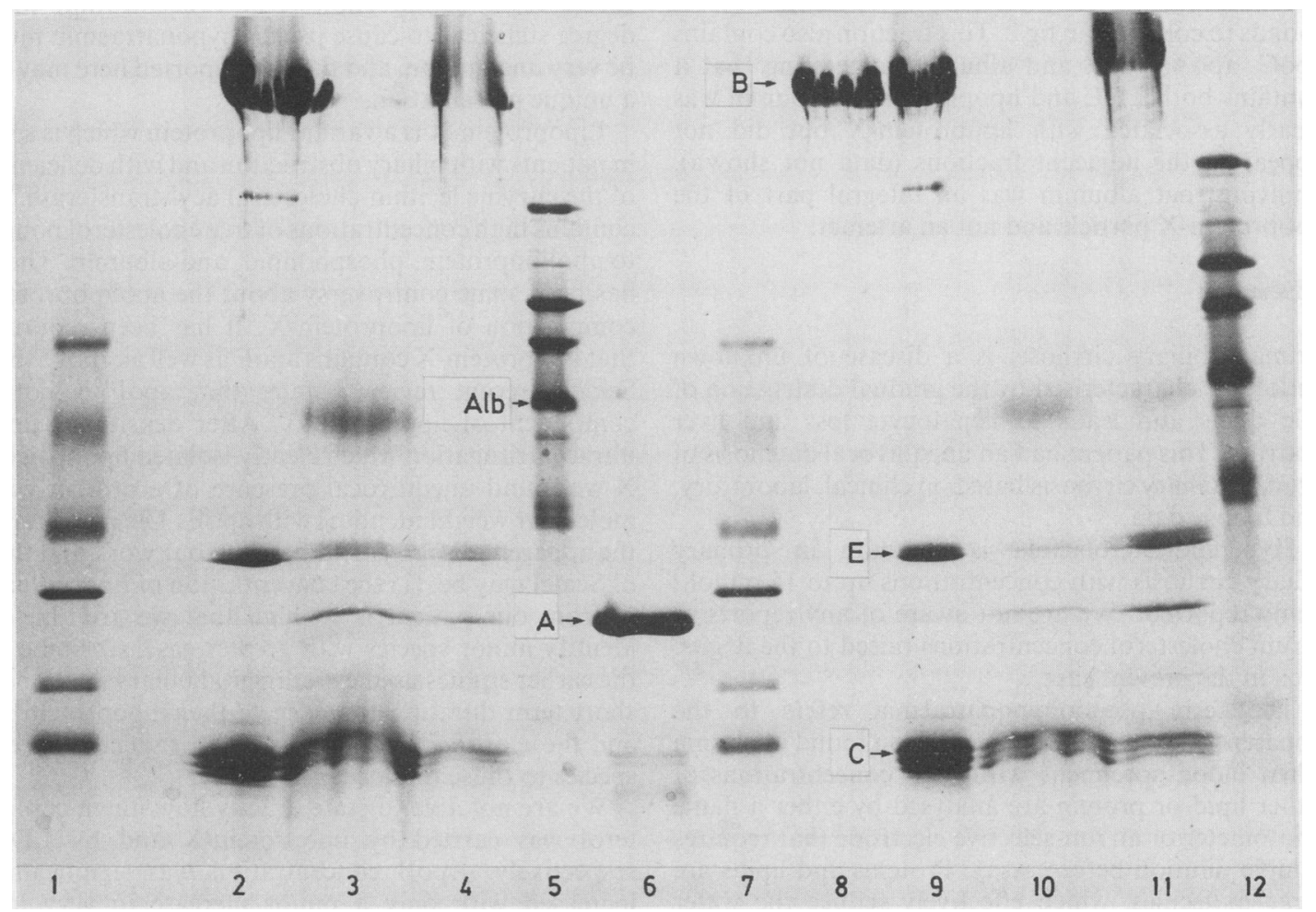

Fig 3 SDS-page. Columns 1 and 7 are high molecular weight markers; columns 5 and 12 low molecular weight markers with the position of albumin identified; columns 2 and 9 are isolated VLDL showing apolipoproteins $C, E$, and $B$; columns 3 and 10 are the fraction of density $1.060 \mathrm{~kg} / \mathrm{l}$ and correspond to column 3 in fig 2; columns 4 and 11 are the fraction of density $1.029 \mathrm{~kg} / \mathrm{l}$ and correspond to column 2 in fig 2; column 6 is an isolated normal HDL fraction providing an apolipoprotein A-I marker; column 8 is isolated normal LDL showing the position of apolipoprotein B 100. 
Volumes were determined by aspirating fractions into tared tubes and calculating from mass and determined density.

Recovery of cholesterol was more than $99 \%$. Although lipoprotein-X was isolated without contamination from LDL, the fraction containing LDL held a considerable quantity of lipoprotein-X. Measurement of the serum apoB concentration gave a value of $2.9 \mathrm{~g} / \mathrm{l}$ (reference range $<1.0 \mathrm{~g} / \mathrm{l}$ ), suggesting that the cholesterol carried by LDL contributed about $10 \mathrm{mmol} / \mathrm{l}^{6}$ to the total serum cholesterol concentration and that by lipoprotein-X most of the remainder. It should be noted that this specimen was collected four weeks after the original specimen at which time the total cholesterol concentration was $64.8 \mathrm{mmol} / \mathrm{l}$.

SDS-polyacrylamide gel electrophoresis was performed on the fractions separated by density gradient ultracentifugation (fig 3). The two patient fractions of interest are shown in columns 10 and 11 . The fraction run in column 10 contains no apoB and therefore no LDL and corresponds to column 3 in fig 2. This fraction does, however, contain apoC, apo A-I, apoE and albumin. The fraction run in column 11 contains LDL as shown by the presence of apoB and corresponds to column 2 in fig 2 . This fraction also contains apoC, apoA, apoE and albumin, suggesting that it contains both LDL and lipoprotein-X. Albumin was clearly associated with lipoprotein-X but did not appear in the adjacent fractions (data not shown), implying that albumin was an integral part of the lipoprotein-X particle and not an artefact.

\section{Discussion}

Primary biliary cirrhosis is a disease of unknown aetiology, characterised by the gradual destruction of bile ducts and leads to hepatocyte loss and liver scarring. This patient had an unequivocal diagnosis of primary biliary cirrhosis based on clinical, laboratory, and biopsy data.

Hypercholesterolaemia is common in primary biliary cirrhosis with concentrations up to $15 \mathrm{mmol} / \mathrm{l}$ being reported.' We are not aware of any reports of serum cholesterol concentrations raised to the degree seen in the present case.

The term pseudohyponatraemia refers to the apparently low sodium concentration found in plasma when blood specimens with high concentrations of either lipid or protein are analysed by either a flame photometer or an ion-selective electrode that requires sample dilution before assay. Proteins and lipids are large molecules, which effectively reduce the water space of plasma (in which sodium is present). Flame photometers measure the amount of electrolyte in a given volume of plasma, without making any correction for variations in plasma water content that may result from either hyperlipidaemia or hyperproteinaemia. Direct reading ion-selective electrodes that do not include sample dilution before measurement determine sodium in the water space of plasma alone, and values obtained are thus independent of variations in the plasma water content. The values obtained with direct reading ion-selective electrodes are considered to be more physiologically correct for planning patient management. ${ }^{7}$ Ion-selective electrodes that require a dilution step before assay produce results more closely resembling those obtained by a flame photometer.

Technical considerations make use of direct reading ion-selective electrodes impractical in automated laboratory equipment. Pseudohyponatraemia of an extent to cause clinically important low sodium concentrations (sodium $<125 \mathrm{mmol} / \mathrm{l}$ ) is extremely uncommon, however, with even large hospital laboratories not seeing more than perhaps one or two cases a year. ${ }^{8}$ Thus no special precautions need or should be taken, save alertness and access to a direct reading ion-selective electrode.

Grossly increased concentrations of triglyceride are commonly associated with pseudohyponatraemia. Increases in serum cholesterol concentration to a degree sufficient to cause pseudohyponatraemia must be very uncommon, and the case reported here may be a unique presentation.

Lipoprotein- $\mathrm{X}$ is a variant lipoprotein which is seen in patients with biliary obstruction and with deficiency of the enzyme lecithin-cholesterol acyl-transferase. ${ }^{9}$ It contains high concentrations of free cholesterol bound to apolipoprotein, phospholipid, and albumin. There has been some controversy about the apolipoprotein composition of lipoprotein-X. It has been reported that lipoprotein-X contains apoE as well as apo $\mathrm{C}^{10}$ but Seidel's recent review" states that apoE is not a component of lipoprotein-X. After density-gradient ultracentrifugation which clearly isolated lipoprotein$\mathrm{X}$ we found unequivocal presence of a protein with molecular weight identical with apoE. The reasons for the apparent disagreement between our work and that of Seidel may be: (1) the concentration of lipoprotein$X$ from our patient is so high that we are able to identify minor species with greater ease; (2) some of the earlier studies used experimental biliary ligation of short term duration to generate their lipoprotein-X, and these artificial conditions may produce different species to those that occur naturally.

We are not able to state exactly how much cholesterol was carried by lipoprotein-X and by LDL, respectively. ApoB concentration was significantly increased with only a minor increase in very low density lipoprotein (the serum triglyceride concentration was $3.5 \mathrm{mmol} / \mathrm{l}$ ), implying that LDL-cholesterol concentration was also increased. Based on the chemical composition of LDL, ${ }^{6}$ the LDL-cholesterol 
was estimated at about $10 \mathrm{mmol} / \mathrm{l}$, a concentration associated with a much increased risk of cardiovascular disease. ${ }^{12}$ The very high serum concentrations of cholesterol seen in this patient raise the question whether there might be some other factor acting with the primary biliary cirrhosis to produce this degree of hypercholesterolaemia, such as familial hypercholesterolaemia or other genetic hyperlipidaemia. We have not been able to carry out a family study to find support for this suggestion. Our patient was being considered for hepatic transplantation, but was considered unlikely to be accepted because of considerable ischaemic heart disease.

\section{References}

1 Jahn CE, Schaefer EJ, Taam LA, et al. Lipoprotein abnormalities in primary biliary cirrhosis. Association with hepatic lipase inhibition as well as altered cholesterol esterification. Gastroenterology 1985;89:1266-78.

2 Redgrave TG, Roberts DCK, West CE. Separation of plasma lipoproteins by density gradient ultracentrifugation. Anal Biochem 1975;65:42-9.

3 Laemmli UK. Cleavage of structural proteins during the assembly of the head of bacteriophage T4. Nature 1970;227:680-5.

4 Connelly PW, Kuksis A. SDS-glycerol polyacrylamide gel electro- phoresis of plasma apoproteins. Biochem Biophys Acta 1982; 711:245-51.

5 Seidel D, Alaupovic P, Furman RH. A lipoprotein characterizing obstructive jaundice: I. Method for quantitative separation and identification of lipoprotein in jaundiced subjects. J Clin Invest 1969;48:1211-23.

6 Kezdy FJ. Physical properties, chemical composition and structure of circulating lipoproteins. In: Peeters $\mathrm{H}$, ed. The lipoprotein molecule. New York: Plenum Press, 1977:83-90.

7 Worth HGJ. Plasma sodium concentration: bearer of false prophecies? Br Med J 1983;287:567-8.

8 Hickman PE, Riley WJ, Moody HR, Hurst P. Occurrence and aetiology of hyponatraemia. Med J Aust 1988;148:602.

9 Torsvic H, Berg K, Magnani HN, et al. Identification of the abnormal cholestatic lipoprotein (LP-X) in familial lecithin: cholesterol acyltransferase deficiency. FEBS Lett 1974;42: 165-8.

10 Patsch JR, Aune KC, Gotto AM, Morrisett JD. Isolation, chemical characterization, and biophysical properties of three different abnormal lipoproteins: LP-X $\mathbf{X}_{1}$ LP-X $\mathbf{X}_{2}$, and LP-X J Biol Chem 1977;252:2113-20.

11 Seidel D. Lipoproteins in liver disease. J Clin Chem Clin Biochem 1987;25:541-51.

12 Kannel WB, Castelli WP, Gordon T. Cholesterol in the prediction of atherosclerotic disease. New perspectives based on the Framingham Study. Ann Intern Med 1979;90:85-91.

Requests for reprints to: Dr J R L Masarei, Department of Biochemistry, Royal Perth Hospital, GPO Box X2213, Perth, Western Australia. 